\title{
Research on The Financing Mode of Small and Medium-sized Enterprises
}

\author{
Zhang Xiaolei \\ School of Economic and Management \\ Shengyang Aerospace University \\ Shengyang, China
}

\begin{abstract}
Looking back at the history of the growth and development of SMEs, regardless of how changes in domestic and international economic environment, and regardless of how domestic economic policy adjustment, the difficult problem of SME financing has been more prominent. Economic situation can lead to SME capital chain rupture, leading to small and medium enterprises into pieces spread throughout the country and even collapse. This paper tries to stand in the point of view of the global supply chain, with special economic region core enterprise supply chain members of the upstream capital demand as the starting point, the thorough specific problems, and use of medium and small-sized enterprises in the supply chain and the core enterprise has the stable business, trade funds and other advantages, combined with the chattel mortgage and the transfer of the creditor's rights mode, study the special economic area small and medium-sized enterprise supply chain operation mode of financing mechanism, participate in the risk and benefit main body.
\end{abstract}

Keywords-Supply chain finance; SMEs; Financing model.

\section{INTRODUCTION}

Currently, the development trend of world economic globalization, regional economic integration has spread rapidly. China has already won the reputation as the world's manufacturing center, but as a great power of modern manufacturing, we must clearly realize that China has a lot of enterprises, especially SMEs, are always at the end of the global industrial chain and value chain. While export-oriented economic development model is hit by the U.S. debt and European debt crisis, and continued downturn of global economy and the sharp decline in trade has severely affected the unsustainable demand.

SME financing has always been the focus of the whole society. As the most important resource, how to guide it flow to the SMEs that in disadvantaged position in the industrial chain and supply chain is the problem that must be solved for a country's overall economic development, while supply chain financing can extend the good credit capacity of core enterprises to the upstream and downstream firms of supply chain after China becoming world manufacturer and global production outsourcing base and on the basis of domestic supply chain management having been prevalent, making up the financing gap existing extensively in SMEs, to relieve SME financing pressure.

\section{SUMMARY OF SUPPLY CHAIN FINANCING}

The early supply chain considers that supply chain as an interior problem of the manufacturer. It refers to a process that transmitting the outsourcing raw material and parts to retailers and users through the activities of transformation and sales and so on. The traditional supply chain concept is restricted to enterprises' interior operational level, focusing on enterprise private resource utilization goal. Later, there's some progress focusing on the relationship with other enterprises and the outer environment of supply chain enterprises, considering it is a "process that transforms the raw material into products and transmits them to end users through manufacturing, assembling and retail processes of different manufacturers in the chain", which is a wider and more systematic definition. But up to now, the supply chain concept take more concern on the network chain relationship around core enterprises, such as the relationship of core enterprises and suppliers, suppliers' suppliers, even all the forward relationships, core enterprises and users, users and users, as well as all the successive relationship, when strategic partnership issues are emphasized more.

Supply chain is a system, the objective reality of human production activities and the whole economic activities. Various products in human activities all belong to the process from raw material production, processing, assembling, distribution and retailing to the final consumption. With the society developing, returned logistics was also incorporated to the system.

\section{THE MAIN MODES OF SUPPLY CHAIN FINANCING AND MODES ANALYSIS}

\section{A. The main modes of supply chain financing}

As the most important part of the supply chain, the safety of SMEs and their upstream and downstream will affect the operation of whole supply chain. Therefore, how to transform financing mode, improve finance service quality for SMEs, and decrease finance costs of the whole supply chain is the key to solve sustainable development problems of supporting the stability of supply chain.

Currently, there are SME financing models taking accounts receivable, prepayments and inventory as collateral depending on the collateral types; therefore, supply chain financing model has three common types: accounts receivable financing, confirming storage financing and chattel mortgage financing. These three 
modes make all the SMEs in the supply chain choose their own mode of financing based on the upstream and downstream trade relations and their own characteristics.

\section{1) Accounts receivable financing mode}

For many SMEs on the stage of development, they have no strong bargaining power. The large enterprises (core enterprises) of their downstream often purchase production material with credit buying; because they have limited capital and cannot reach bank credit standard, their working capital limitation restricts the enterprises' further development. Accounts receivable financing mode is created under such conditions, which is just the customized product for SMEs' accounts receivable. The main process includes the SMEs on the upstream of core enterprises apply for financing from banks with undue receivables (core enterprises).

\section{2) Confirming storage financing mode}

Confirming storage financing mode is generated under the conditions that the SMEs lying at downstream of the supply chain core enterprises purchase goods to prepare new production activities, but at this time the companies do not have sufficient cash flow; Therefore, in order to solve the problem of capital shortage and make them produce, the specific processes includes downstream SMEs pay a certain amount of security deposit to financing banks and the bank will open corresponding acceptance draft in accordance with the enterprises conditions, and the financing bank will accept the draft, the beneficiary is the core enterprise on the upstream of financing enterprise. After receiving the draft, the upstream enterprises will start to deliver goods to the bank designated warehouse of the third-party logistics company, the goods will be transformed into pledge by warehouse receipts after arriving at the warehouse, while downstream SMEs apply for financing business on the condition that the core enterprise can control its goods collection right.

\section{3) Chattel mortgage financing mode}

In a specific period, too much inventory of SMEs will occupy a lot of capital, but the enterprises also need to buy raw material, so SMEs can take the bank recognized goods as pledge to apply for financing, which is chattel mortgage financing, also called "inventory financing". The chattel mortgage financing can support many kinds of financing methods, including loan, opening bank acceptance draft, letter of credit and so on. The enterprises can choose suitable financing method according to their own conditions. The specific application process is that the SMEs need to deliver their own legal and accessed inventory to the designated third party logistic company of the bank for supervision without ownership. Inventory financing mode is more flexible and convenient, given that the inventory is recognized by the bank, they can be served as the pledge. This mode allows the enterprise not only get the financing, but without affecting normal production and operation, so it is easy to promote and apply in actual operation.

\section{B. Model building and analysis of three financing modes}

We remove some unnecessary disturbance in building models to establish more ideal math models suitable for various models; so we make the following assumptions: (1) the involved people and enterprises and organizations of these three models are rational men, so the signed agreements in financing-transportation and warehouse financing mode, cargo value assessment, acceptance and related work all conform to objective conditions. In confirming storage financing mode, core enterprises cooperate with the bank actively to assess and approve their credit and sign repurchase agreement, and the third party logistic company will also sign storage supervision agreement. In account receivable mode, the core enterprises conform to the requirements completely and can remit to designated account. (2) Financing enterprise and the bank grasp completely symmetric information and strategy.

\section{1) Chattel mortgage financing mode}

both parties game model assumption

Given the possibility of bank lending as $P_{1}$, then the possibility without lending of bank is $1-P_{1}$; given the pledge total amount of SMEs in the market is $T_{1}$, the loan scale in the market is about $\mathrm{G}$

Given the capital rate of return of SMEs is $\alpha$, loan interest rate is $r$, loan time is $d$, the final total value of bank estimated pledge is $T_{1}$; the payment for the third party logistics by the bank as $\mathrm{f}$

The penalty and reputation loss of repayment not on time for the enterprise is $\mathrm{L}$

2) The SMEs repayment probability is $P_{21}, U J_{n}$ means the bank lend to enterprises, but they default repayment or even violate the agreement without repayment.

TABLE I BANK AND SMES GAMING MODEL

\begin{tabular}{|c|c|c|}
\hline & SMEs & Bank \\
\hline Repay on time & $G \alpha-G r d$ & Grd - f \\
\hline $\begin{array}{l}\text { Default no } \\
\text { repayment }\end{array}$ & $G(1+\alpha+\mathrm{r} d)-T_{2}-L$ & $T_{2}-f-G(1+r d)$ \\
\hline $\begin{array}{l}\text { from the prospe } \\
\text { expectation } \\
\qquad M z=P_{1}(G \alpha-\end{array}$ & 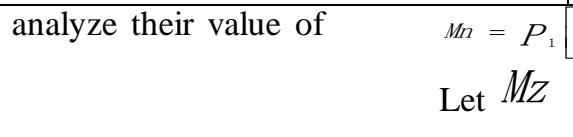 & $\begin{array}{l}{\left[G(1+\alpha+r d)-T_{2}-L\right]} \\
=M n \text { and get: }\end{array}$ \\
\hline
\end{tabular}




$$
\mathrm{r}=\frac{T_{2}+L-G}{2 G d}
$$

So the higher of final value of the pledge of bank lending is higher, the higher of lending interest rate, the more possibility of bank lending; under this assumption, final value of the pledge is the important considering factor of bank loading.

from the prospect of banks to analyze their value of expectation

$$
\begin{aligned}
& U_{d}=P_{21}(G r d-f) \\
& U_{n}=\left(1-P_{21}\right)-T_{2}-f-G(1+r d)
\end{aligned}
$$

Let $U_{d}=U_{n}$ is: Let $U_{d}=U_{n}$, and get:

$$
P_{21}=1-\frac{\mathrm{Gr} d-f}{T_{2}-2 f-G}
$$

Because $\quad P_{21}>0$

Grd - $f>0 T_{2}-2 f-G>0$

$$
\frac{\partial \mathrm{P}_{21}}{\partial r}=-\frac{G d}{T_{2}-2 f-G}<0
$$

When $P_{21}>1-\frac{G r d-f}{T_{2}-2 f-G}$, the bank will lend,

unless won't. Through further calculation, the

$$
\text { derivation is: } \frac{\partial \mathrm{P}_{21}}{\partial r}=-\frac{G d}{T_{2}-2 f-G}<0
$$

So the load paying rate of the borrowing enterprise is in inverse proportion to lending rate. If the final total value of the pledge is higher, the load paying rate is higher.

3) Confirming storage financing mode

both parties game model assumption

Given the possibility of bank lending as $P_{1}$, then the possibility without lending of bank is $1-P_{1}$; the loan scale in the market is about $\mathrm{G}_{2}$

Given the capital rate of return of SMEs is $\alpha$, loan interest rate is $\mathrm{r}$, loan time is $\mathrm{d}$, the penalty for core enterprises resulted from borrowing enterprises default is $\mathrm{Z}$; the security cost paid by borrowing enterprises to the third party logistics is $f_{2}$, and the penalty for their guarantee enterprises made by the third party logistic enterprises is $\mathrm{K}$

The penalty and reputation loss of repayment not on time for the enterprise is $\mathrm{L}$

Loan paying probability of SMEs is $P_{22}$

TABLE II CONFIRMING STORAGE FINANCING MODE BANK AND SMES GAMING MODEL

\begin{tabular}{c|c|c}
\hline & SMEs & Bank \\
\hline Repay on time & $G_{2} \alpha-G_{2} r d-f_{2}$ & $G_{2} r d$ \\
\hline Default no repayment & $G_{2}(1+\alpha+r d)-f_{2}-K-L$ & $Z-G_{2}(1+\mathrm{rd})$ \\
\hline
\end{tabular}

from the prospect of SMEs to analyze their

value of expectation

$$
\begin{gathered}
M_{z}=P_{1}\left(G_{2} \alpha-G_{2} r d-f_{2}\right) \\
M_{n}=P_{1}\left[G_{2}(1+\alpha+r d)-f_{2}-\mathrm{K}-\mathrm{L}\right] \\
\text { Let } M_{z}=M_{n}, \text { and get: } \\
\frac{\mathrm{L}+\mathrm{K}-\mathrm{G}_{2}}{2 \mathrm{dG}_{2}}=\mathrm{r}
\end{gathered}
$$

So the higher of the penalty amount $\mathrm{K}$ from the guarantor enterprise paying the third party logistic enterprise for their default, the higher of lending interest rate, the more possibility of bank lending; under this assumption, the penalty amount for financing enterprice is the important considering factor of bank loading.

from the prospect of banks to analyze their value of expectation

$$
\begin{aligned}
& \mathrm{U}_{d}=P_{2} G_{2} r d \\
& U_{n}=\left(1-P_{22}\left[Z-G_{2}(1+r d)\right]\right. \\
& \text { Let } U_{n}=U_{d} \text {, and get: } \\
& P_{22}=1-\frac{\mathrm{r} d G_{2}}{Z-G_{2}} \\
& 1 \geq P_{22}>0, Z>\mathrm{G}_{2}(1+r d) 。 \\
& \text { Because } 1 \geq P_{22}>0, Z>\mathrm{G}_{2}(1+r d)
\end{aligned}
$$


when

$$
P_{22}>1-\frac{\mathrm{r} d G_{2}}{Z-G_{2}} \quad U_{d}=U_{n},
$$$$
\frac{\partial \mathrm{P}_{22}}{\partial \mathrm{r}}=-\frac{d G_{2}}{Z-G_{2}}
$$

When $P_{22}>1-\frac{\mathrm{r} d G_{2}}{Z-G_{2}}, U_{d}=U_{n}$ the bank will lend, unless won't. Through further calculation, the derivation is: $\frac{\partial \mathrm{P}_{22}}{\partial \mathrm{r}}=-\frac{d G_{2}}{Z-G_{2}}$

When $\mathrm{G}_{2}<Z$, the load paying rate of the borrowing enterprise is in inverse proportion to interest rate, then the core enterprise has to bear the risk by themselves. So under confirming storage financing mode, increasing the penalty for core enterprises and controlling interest rate can increase the possibility of paying the loan by financing enterprises.

Accounts receivable financing mode

both parties game model assumption

Given the possibility of bank lending is $P_{1}$, the total amount of account receivable is $Q$, and the lending rate that the bank determines according to its own situations and analysis of market prospect is $\beta$.

Given the SMEs capital rate of return is $\alpha$, loan interest rate is $r$, borrowing time is $d$, the generated cost from the bank lending to financing enterprise is $j$.

$L$

The penalty and reputation loss of repayment not on time for the enterprise is $\mathrm{L}$

Loan paying probability of SMEs is $P_{23}$

TABLE III ACCOUNT RECEIVABLE FINANCING MODE BANK AND SMES GAMING MODEL

\begin{tabular}{c|c|c}
\hline & SMEs & Bank \\
\hline Repay on time & $Q \alpha \beta-Q \beta r d$ & $Q \beta r d-j$ \\
\hline Default no repayment & $Q \beta(1+r d+\alpha)-Q-L$ & $Q-Q \beta(r d+1)-j$ \\
& & \\
\hline
\end{tabular}

from the prospect of SMEs to analyze

$$
\begin{aligned}
& M Z=P_{1}(Q \beta \alpha-Q \beta r d) \\
& M n=P_{1}[Q \beta(1+r d+\alpha)-Q-L]
\end{aligned}
$$$$
\text { let } M n=M Z \text { is: Let } M n=M Z \text {, and get: }
$$

$$
\frac{1}{2 \mathrm{~d} \beta}-\frac{1}{2 d}+\frac{L}{2 d Q \beta}=r
$$

Under the account receivable financing mode, loan rate $\beta$, total account receivable $Q$, the penalty and reputation loss of repayment not on time for the enterprise $L$ all will affect the loan interest rate of bank.

from the prospect of banks to analyze

$$
\begin{aligned}
U_{d} & =P_{23}(Q \beta r d-j) \\
U_{n} & =\left(1-P_{23}[Q-Q \beta(r d+1)-j]\right.
\end{aligned}
$$

Let $U_{d}=U_{n}$, and get:

$$
\begin{aligned}
P_{23} & =1-\frac{Q \beta r d-j}{Q-Q \beta-2 j} \\
0<P_{2} & <1 \quad Q \beta r d-j>0 \\
P_{23} & =1-\frac{Q \beta r d-j}{Q-Q \beta-2 j}
\end{aligned}
$$

when

$$
\frac{\partial P_{23}}{\partial r}=\frac{Q \beta}{Q-Q \beta-2 \mathrm{j}}
$$

$$
\begin{gathered}
\text { Because } 0<P_{2}<1, \text { then } Q \beta r d-j>0, \\
P_{23}=1-\frac{Q \beta r d-j}{Q-Q \beta-2 j}, U_{d}=U_{n} \text { the bank will }
\end{gathered}
$$
lend, unless won't. Through further calculation, the derivation is: $\frac{\partial P_{23}}{\partial r}=\frac{Q \beta}{Q-Q \beta-2 \mathrm{j}}$.

From the actual conditions, we can see $f<\frac{Q-Q \beta}{2}$

paying probability of $\beta$. $\beta$ and total account receivable $Q$ will all affect the repayment of enterprises.

It is well known that timely repayment probability of financing enterprises depends on the bank loan interest rate $r$, they are in direct proportion, that is, if the bank loan interest rate $r$ is higher, repayment probability of borrowing enterprises will be higher; if the probability of keep faith is lower, the bank will require more pledge value $^{T}$, default amount of claim $z$ and pledge account receivable amount $Q$.

\section{Comparison of three models results}

Next we will compare the repayment probability of borrowing enterprises under three models $\begin{array}{llll}P_{21} & P_{22} & P_{23}\end{array}$. 


$$
\begin{aligned}
& P_{21} \quad \text { and } \quad P_{22} \text { : when } Z-\mathrm{G}_{2}>0 \text {, } \\
& \frac{\mathrm{r} d G\left(T_{2}-G\right)}{2 r d G_{2}+G_{2}-Z}>0 \\
& \mathrm{~T}_{2}-2 \mathrm{f}-G>0 \quad, \quad \text { and } \quad \overline{2 r d G_{2}+G_{2}-Z}>0 \\
& P_{21}>P_{22} \text {, }
\end{aligned}
$$

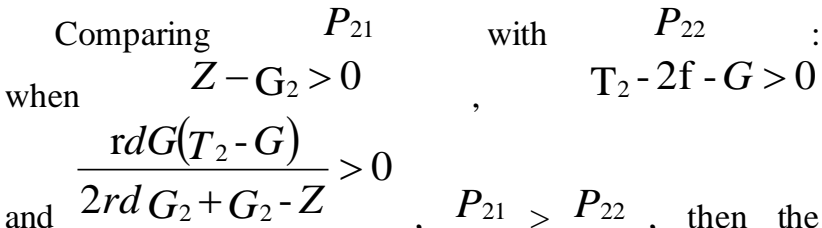

repayment probability of finance-transportation and warehouse financing model is higher than confirming storage financing model.

$$
\begin{aligned}
& P_{22} \text { and } P_{23} \text { compare with : } \\
& Q-Q \beta-2 j>0 \text {,and } \frac{\operatorname{Qrd}\left[G_{2}-\beta Z\right]}{2 d r G_{2}-Z+G_{2}}>j \text {, } \\
& \operatorname{Qrd}\left[\left[G_{2}-\beta Z\right]\right. \\
& P_{22}<P_{23} ; \mathrm{j}<2 d r G_{2}-Z+G_{2} \text {, } \\
& \text { Comparing } P_{22} \text { and } P_{23} \text { : when } Q-Q \beta-2 j>0 \\
& \text { and } \frac{\operatorname{Qrd}\left[G_{2}-\beta Z\right]}{2 d r G_{2}-Z+G_{2}}>j, P_{22}<P_{23} \text {, that is, when } \\
& \text { bank's loan cost } \mathrm{j} \text { is less than } \frac{\operatorname{Qrd}\left[G_{2}-\beta Z\right]}{2 d r G_{2}-Z+G_{2}} \text {, the }
\end{aligned}
$$
repayment probability of pledge of accounts receivable for SMEs is higher than the probability of keep faith of confirming storage financing.

paring $P_{21}$ with $P_{23}$ : these two financing modes have pledge issues. Under these two conditions, the bank will consider on the premise to use the pledge to make up its loss. We compare them in two ways: (1) given that the payment $\mathrm{f}$ for the third party logistic and storage enterprise under financing-transportation and warehouse mode is the same with the bank's loan cost $j$ under account receivable financing mode, we can get: with the same loan scale, the pledge value should be changed with repayment probability. Actually, the bank can grasp the value of pledge to avoid the loan risks under different financing modes.

In conclusion, when the bank spends inviting the third party logistics, it's better not to use confirming storage financing, because the default rate will be the highest, and financing-transportation and warehouse mode and account receivable financing mode default rate will be lower.

\section{CONCLUSION}

The paper starts from supply chain financing prospect, analyzing and solving the financing difficulties of SMEs and proposes corresponding suggestions. Also, it deepens to research the situations of SMEs financing difficulties, analyzes the limitations and establishes models to analyze the differences of these three models. At last, the paper proposes some advice and effective ways to help SMEs walk out from the financing difficulty.

The practice has proved that supply chain financing is an effective way to solve SMEs financing and opens up a new way of financing. With economic globalization deeper, in the next decades, the process that Chinese enterprises entering global economic supply chain will not change. It's undoubted that supply chain financing will increase with higher speed. But with the business development, we also need to see the existing problems of various models or the points that need to be improved. These problems need the effort of enterprises, financing organizations, government and many parties to solve. We should keep researching and exploration, making supply chain finance can play more important role in solving SMEs financing and effective financing issues.

\section{REFERENCES}

[1] T.William, Walker,Alber.Understanding Supply Chain Management.APICS. [A], 1999, 99(1):75-77.

[2] Chen Xiaohong, Chen Jianzhong. SMEs supply chain financing [M].Beijing: Economic science press,2008:4-5

[3] Xie Weiqi. Chinese SMEs financing difficulties - countermeasure research based on supply chain financing [D].Xiamen University, 2009.

[4] Yu Zhaoyun. SMEs supply chain financing model discussion [J].Market modernization, 2008(18) : 180-181

[5] ZhaoHui. Chinese SMEs new financing models research-taking supply chain financing as example[D]. Master's thesis, Ocean University of China, 2009.

[6] Jiang Chaofeng. Development and issues of supply chain finance service [J]. China storage and transportation. 2008(7): 51 52.

[7] Quan Jing. Supply chain financing, innovative finance service [J]. Domestic and foreign logistics. 2008(7):43 44.

[8] Lou Dong, Qian Zhixin. Supply chain financing model analysis and risk prevention [J]. Internet wealth2008(9): 103 104.

[9] Zhao Li. Supply chain financing is an effective way to solve SMEs financing difficulties[J].Shandong economic strategy research.2008(8):60 61. 